\title{
Massage Therapy in Management of Occupational Stress in Emergency Medical Services Staffs: a Randomized Controlled Trial
}

\author{
Mahdi Mahdizadeh, BSc, ${ }^{1}$ Ali Ansari Jaberi, MSc, ${ }^{2}$ Tayebeh Negahban Bonabi, $\mathrm{PhD}^{3 *}$ \\ ${ }^{1}$ Critical Care Nursing Student, School of Nursing and Midwifery, Students Research Committee, Rafsanjan University \\ of Medical Sciences, Rafsanjan, Iran, ${ }^{2}$ Department of Psychiatric and Mental Health Nursing, School of Nursing and \\ Midwifery, Social Determinants of Health Research Center, Rafsanjan University of Medical Sciences, Rafsanjan, Iran, \\ ${ }^{3}$ Department of Community Health Nursing, School of Nursing and Midwifery, Social Determinants of Health Research \\ Center, Rafsanjan University of Medical Sciences, Rafsanjan, Iran
}

Background: Results of various studies indicate that emergency medical service (EMS) staff suffer from occupational stress that adversely affects their quality of life and their care quality.

Purpose: This study aimed at determining the effect of massage on occupational stress experienced by emergency medical service staff.

Setting: Prehospital emergency medical services stations of a city in the southwest of Iran.

Participants: A total of 58 members of staff of the emergency medical services, working in prehospital emergency medical services stations.

Research Design: In this randomized controlled trial, a total of $58 \mathrm{EMS}$ staff were selected from prehospital EMS stations, according to inclusion and exclusion criteria, and then assigned in two groups (29 in massage and 29 in control group) randomly by the minimization method. The intervention group received Swedish massage, twice a week for four weeks in the morning after the end of the work shift. Each massage session lasted 20-25 minutes. Subjects in the control group received no intervention. The level of occupational stress of the two groups was measured under the same conditions before and after the intervention by using the expanded nurses' occupational stress scale (ENSS). Data were analyzed with the SPSS16 software by using the chi-squared test, paired and independentsample $t$ tests, one-way ANCOVA. $P$ value $<.05$ was considered as the level of significance.

Results: The mean and SD of total occupational stress scores in the control group was $114.41 \pm 30.11$ in pretest and reach to $112.58 \pm 30.62$ in posttest stage. Also the mean and SD of total occupational stress scores in the intervention group was $130.20 \pm 26.45$ in pretest and reach to $110.41 \pm 21.75$ in posttest stage. A one-way ANCOVA showed that there is a significant effect of massage on EMS staff's occupational stress level after controlling for pretest score $(p=\mathbf{. 0 0 1})$.

Conclusions: The training and the application of massage therapy can serve as an effective method in reducing occupational stress in emergency medical centers.

KEY WORDS: complementary medicine; emergency medical services; massage therapy; occupational stress; job stress

\section{INTRODUCTION}

The Emergency Medical Services (EMS) staff often constitutes the first professionals who attend stressful medical situations, providing care to injured people and those who are critically ill, suspended between life and death. Thus, these individuals are often exposed to specific conditions in which they experience occupational stress. The findings of certain studies have demonstrated that $55.5 \%$ of emergency nurses suffer from extreme occupational stress. ${ }^{(1)}$ Most of them have reported exposure to injured children from accidents, ${ }^{(2,3)}$ death,${ }^{(4)}$ burns, ${ }^{(5)}$ and scenes of violence and accidents ${ }^{(6)}$ as significant stressful situations. Other stressful situations for these professionals include a lack of access to physicians, nonsupportive management, patient's companions, shift work, working with patients with mental disorders, ${ }^{(7)}$ or patients with behavioral problems or drug abuse and alcohol abuse, ${ }^{(8)}$ or who present violent aggressive behaviors. Moreover, certain scholars have referred to other factors such as a heavy workload, ${ }^{(9)}$ role conflicts, ${ }^{(10)}$ perception of little organizational support, ${ }^{(9)}$ and personal psychological aspects ${ }^{(9,11)}$ as parameters related to the perceived stress in these individuals. In addition to the issues mentioned above, emergency medical service staff employed in the government health-care system in Iran, are involved in handling various other challenges, such as the shortage of personnel, insufficient equipment, deficient training with respect to the necessary standards, problems of interaction with others, problems of skill training, exposure to worries, and various forms of emotional distress. ${ }^{(12)}$ 
Chronic exposure of the emergency medical services staff to unpredictable stressful conditions has led to certain scholars classifying these individuals as persons exposed to a high risk of PTSD. ${ }^{(13,14)}$ In addition, if sufficient attention is not paid to stress and if such stress is not properly managed using correct methods, it may predispose EMS staff to numerous physical and psychological symptoms. ${ }^{(15)}$ Some of these symptoms may include anxiety, $(16,17)$ depression, ${ }^{(12)}$ gastrointestinal symptoms, backache, ${ }^{(18)}$ sleep disorders, fatigue and unsafe behavior, ${ }^{(19)}$ diminished occupational satisfaction, ${ }^{(20)}$ occupational burnout, ${ }^{(21)}$ emotional disturbance, and depersonalization. ${ }^{(22,23)}$

Furthermore, occupational stress may result in behavioral problems, such as turning to alcohol consumption $^{(21,24)}$ and work leave, ${ }^{(14)}$ which ultimately destroys and wastes resources, and imposes certain extra costs on the health-care system, ${ }^{(16)}$ leading to low-quality care and reduced patient safety. $(25,12)$

Scholars have paid attention to the coping skills for occupational stress, offering various methods for accommodation for occupation-related stressors for the emergency medical service staff. $(22,26,27)$ Moreover, certain approaches have been put forward with regard to coping with occupational stress; among them are the use of traditional complementary therapeutic methods like aromatherapy, music therapy, and massage therapy.

Massage therapy is one of the publicly favored methods of complementary medicine. Although it has been offered mostly for pain management, recent studies have recommended the use of this therapeutic modality for situations like fostering the development and growth of immature or premature neonates, suppressing depression and anxiety, increasing attention and concentration, and correcting the performance of the immune system. ${ }^{(25)}$

A review of the literature reports a contradictory collection of findings with regard to the effect of massage therapy on the rates of nurses' occupational stress. Some of these studies have reported no effect of this type of intervention on reducing occupational stress, ${ }^{(8)}$ while some other studies have reported a reduction in occupational stress due to the application of massage therapy. ${ }^{(25,28)}$ Consequently, in a systematic review, scholars have recommended that certain high-quality clinical trials be conducted to investigate the extensive use of the various types of interventions for managing occupational stress among health-care personnel. ${ }^{(3)}$

Considering the unavoidability of certain stressful parameters in the EMS profession and the necessity of preventing its physical, psychological, and behavioral consequences to improve patient safety, quality of care, and their quality of life, as well as the necessity of staff training and the application of lowcost effective methods for coping with occupational stress among these individuals, this study aims to answer the following research question: What is the effect of the massage therapy on occupational stress among EMS staff? It was hypothesized that massage therapy results in a reduced occupational stress level among EMS staff.

\section{METHODS}

This randomized controlled trial was carried to determine the effect of Swedish massage on occupational stress in the EMS staff in Rafsanjan in the Kerman Province, Iran.

The EMS staff in Iran comprise a combination of nurses, nurse aides, and EMS technicians. These professionals work round-the-clock and all of them are male. EMS delivery is financed by government and is free of charge. The standard for a response time is less than eight minutes in cities (except Tehran, the capital of Iran) and less than 15 minutes in suburban areas for $80 \%$ of cases.

Main outcome measure was occupational stress level. The study was performed in EMS centres of Rafsanjan University of Medical Sciences in Kerman Province. In Rafsanjan, there are 20 EMS centres (16 in suburban area and 4 in the city).

On the whole, 58 individuals selected (29 participants in each group) based on a previous study. ${ }^{(26)}$ The confidence level of $95 \%$, the power of $80 \%$, the reported standard deviation for occupational stress level 6.75, and the effect size of 3.5, based on reported the minimum difference between the means, were considered.

After approval of the research project, one of the researchers, who was a member of the EMS facility, gave presentations to the EMS centres at Rafsanjan, surveyed the personnel of these centers for certain inclusion criteria, and asked them to voluntarily participate in the study. The participants were assigned into the intervention and the control groups on the basis of categories of age and work experience by using the minimization method. ${ }^{(29)}$ The categories were $20-30$ and $30-40$ years for the age variable and $<10$ years and $>10$ years of employment for the work experience variable. The participants were randomly assigned into the categories of the two groups such that the total number of samples in each category was equal. Sampling continued until the required sample volume was reached.

Before intervention, the ENSS was completed by all of the participants in the two groups (pre-test). To minimize the effect of bias, the individual who measured the stress was someone else other than researcher therapist via face-to-face interviews.

\section{Participants}

The inclusion criteria were as follows: at least one year of experience of working in the emergency ward; 
inclination for voluntary participation in the massagetherapy program; not receiving any other treatment alongside relaxation techniques such as yoga and meditation; no administration of tranquilizers, narcotics, or anti-anxiety drugs; the absence of edema, inflammation, or neuropathy in the massage site; and the lack of affliction with acute or chronic diseases affecting the psychological status of the individual. The exclusion criteria were as follows: the lack of inclination for continuing participation in the study, and losing the inclusion criteria during the study.

\section{Intervention}

The intervention was performed in the rest area of the personnel, which was a quiet, private, clean, hygienic, safe, and a noiseless place with no disturbance and good air-conditioning. The massage used in this study was the Swedish (classic) massage, which consisted of the three main movements: effleurage, petrissage, and percussion. The effleurage had a slow rhythmic movement and was performed with the open palms of hands, which consisted of moderate pressure that initiating from up part of massage area and going all way till the down part to release the trapped strain. The strokes were stretched, consistent, and flat, maintaining contact with the subject's body as much as possible. In petrissage techniques, the therapist performed a rhythmic, alternating push-pull motion. In this phase, therapist worked toward pulling the muscles apart from the bone by squeezing, kneading, and rolling the muscles to release toxins trapped them. In percussion phase, therapists delivered rhythmic movements via consistent strikes from his wrists, fingers, two sides of the hands, as well as fists, to achieve better massage goal.

Massage was carried out in back, shoulders, arms, hands, legs, and feet. All areas of the body which are not being treated were covered with a disposable towel to ensure subjects privacy and warmth. Massage sequence was back, shoulders, back of left leg, back of right leg. Then subjects turned over to a supine position and the massage continued to the left leg and foot, right foot and leg, right arm and hand, left arm and hand. The subjects were advised to drink water to flush out toxins and to rest after treatments to optimize massage effects. In all movement of the massage, the therapist assessed the subjects and adopted procedure consistent with their desire and preference. The Swedish massage program was performed for the intervention group by one of the researchers who was trained in massage and who had obtained the certificate of Swedish massage therapy. To perform this massage, the researcher used the palms of both hands with the fingers close together, and the massage maneuvers were performed by applying moderate pressure. ${ }^{(30)}$ The researcher's hands were not separated from the body of the participants during the procedure, while the client lay down in a relaxed manner with feet separated to the width of the shoulders so that no strain was applied to the feet. The therapist was careful to note that the nails of the participants were clipped with no rings on their fingers, which might damage the client's skin. The researcher wore light comfortable clothes during the intervention and the participants also used comfortable disposable cloths for each session. They were then allowed to lie down on the bed for 3-5 minutes with a relaxed mind, wearing the aforementioned clothes. The researcher therapist applied the special massage oil on his hands before commencing the massage and rubbed it on his hands to make them sufficiently warm and soft. The applied oil was Firooz moisturizing baby oil which is free of essence, colour, conservator agents, and vitamins, and is appropriate for baby and adult body massage. Then, he began to perform the procedure. The massaging intervention was performed twice a week with 1-2 days interval between massage sessions (depending on the staff's work shift). The average duration of massage for each part of the body (back and shoulder, arms and hands, legs and feet) was 20-25 minutes. The mean time for shoulder and back was 25 minutes, arms and hands 20 minutes, and the legs and feet 25 minutes. The mean of total time of the massage lasted 60-70 minutes, depending on the subject's conditions. Intervention was carried out in the morning after the end of the work shift. It should be pointed out that the work shift of the participants was diurnal (24 hours). This was continued for four weeks. ${ }^{(31)}$

No intervention was performed on the participants in the control group of the study. Immediately after the completion of the almost one month of intervention, the occupational stress questionnaire was once again provided to the participants in both groups.

\section{Measurement and Data Collection}

Data-collection instruments included two inventories:

1. Demographic information questionnaire including age, years of work experience, number of work hours per month, marital status, occupational status (full-time, part-time), and exercise record.

2. The expanded nurse's stress scale (ENSS). The ENSS includes 57 items. It is scored using a 5 -point Likert scale, ranging from 0 to 4 , in which the samples answer the items in terms of the frequency of their experience in the intended situation. On this scale, $0=\mathrm{I}$ have never faced such a situation, 1 = I feel no stress, $2=$ Sometimes, I feel stressful, $3=$ I often feel stressful, and $4=$ I am extremely stressful. ${ }^{(32)}$ A greater score on the scale indicates a greater degree of tension. ENSS contained nine subscales including Death and Dying, Conflict with Physicians, Inadequate Emotional Preparation, Problems Relating to Peers, Problems Relating to Supervisors, Work Load, Uncertainty Concerning Treatment, $\mathrm{Pa}$ tients and their Families, and Discrimination. 


\section{Ethical Consideration}

The study protocol was approved by the Committee of Ethics in Research from the Research Council of Rafsanjan University of Medical Sciences under the ethics code: 113.1395. To diminish the induced effects of intervention on the dependent variable in this study, the participants were not completely informed of the goals of the study, despite the fact that informed written consent was obtained from each of them by completing a request form for receiving massage therapy. Hence, they received massage therapy as a complementary medicine method.

This trial registered in Iranian Registry of Clinical Trials with clinical trial registration number: IRCT20171223038023N1

\section{Statistical Method}

Data were analyzed by SPSS version 16 (SPSS Inc., Chicago, Illinois, USA), using descriptive statistics, the Kolmogorov-Smirnov, Chi-square, paired and independent-samples $t$ tests, and the one-way ANCOVA. $P$ value less than .05 was considered as level of significance.

\section{RESULTS}

In the current study, a total of 59 EMS staff was selected out of the 110 staff based on the inclusion and the exclusion criteria of the study, and they were assigned to two groups. One person was excluded from the intervention group due to unwillingness to continue massage sessions.

To evaluate the normal distribution of data, the results of the Kolmogorov-Smirnov test showed the normal distribution in the variables. Hence, parametric tests were used to analyze the data.

Of the 59 participants, 11 were nurses (Bachelor's or Master's degree), 46 were medical emergency technicians, and one was an anesthetist technician. The mean \pm SD of subject's age was $29.74 \pm 3.80$ years, with minimum of 24 and maximum 40 years, also mean \pm SD of their duration of employment was $7.52 \pm 3.71$ years with minimum 2 and maximum 15 years. For number of work hours per month the mean \pm SD was $286.59 \pm 69.79$ hours. The subjects had minimum of 120 and maximum of 400 work hours per month. The results show that the two groups were matched in mean $\pm \mathrm{SD}$ of age, duration of employment, number of work hours per month, marriage status, and the performance of exercise (Table 1).

In the control group, the mean $\pm \mathrm{SD}$ of total stress score in pre-test was $114.41 \pm 30.11$ to $112.58 \pm 30.62$ in post-test phase. The result of the total occupational stress score in the evaluation inside groups showed no significant difference between pre-test and post-test in the control group. In addition, with the exception of the conflict with the physician's subscale, in other subscales, there was no statistical difference between the pre-test and the post-test in the control group (Table 2).

However, in the intervention group, the mean \pm SD of total stress score in pre-test phase was 130.20 \pm 26.45 and was reduced to $110.41 \pm 21.75$ after intervention. Comparing the pre-test and the post-test scores of the total occupational stress and all the subscale scores in intervention group shows a significant difference $(p<.05)$ (Table 3$)$.

TABLE 1. Comparison of Demographic Characteristics of Subjects in Intervention and Control Groups

\begin{tabular}{|c|c|c|c|c|}
\hline & & Massage Group & Control Group & \\
\hline & & Mean $\pm S D$ & Mean $\pm S D$ & \\
\hline Age & & $29.93 \pm 3.54$ & $29.55 \pm 4.11$ & .70 \\
\hline Duration of emp & oyment & $7.76 \pm 3.75$ & $7.28 \pm 3.72$ & .62 \\
\hline $\begin{array}{l}\text { Number of mont } \\
\text { hours }\end{array}$ & ly work & $287.79 \pm 69.85$ & $285.38 \pm 70.95$ & .89 \\
\hline & & Frequency (\%) & Frequency (\%) & \\
\hline Marriage Status & Married & $22(38)$ & $22(38)$ & 100 \\
\hline Doing Exercise & Single & $7(12)$ & $7(12)$ & 1.00 \\
\hline & Yes & $11(19)$ & $13(22.4)$ & 305 \\
\hline & No & $18(31)$ & $16(27.6)$ & (395 \\
\hline
\end{tabular}

Using independent $t$ test and Chi Square test.

$p<.05$

TABle 2. Comparing Pre-Test and Post-Test Score of the Total Occupational Stress and all Subscales Scores in Control Group

\begin{tabular}{lccc}
\hline & Post-Test & Pre-Test & $p$ \\
\cline { 2 - 3 } & Mean $\pm S D$ & Mean $\pm S D$ & value \\
& $15.00 \pm 4.42$ & $4.29 \pm 14.93$ & .77 \\
Death and Dying & $9.82 \pm 2.82$ & $2.69 \pm 9.24$ & .001 \\
Conflict with Physicians & $6.00 \pm 1.83$ & $2.07 \pm 6.00$ & 1.00 \\
$\begin{array}{lccc}\text { Inadequate Emotional } \\
\text { Preparation }\end{array}$ & $10.62 \pm 2.90$ & $4.85 \pm 10.72$ & .88 \\
$\begin{array}{l}\text { Problems Relating to Peers } \\
\text { Problems Relating to }\end{array}$ & $14.06 \pm 4.97$ & $4.87 \pm 14.17$ & .73 \\
$\begin{array}{l}\text { Supervisors } \\
\text { Work Load }\end{array}$ & $4.42 \pm 18.64$ & $5.35 \pm 18.17$ & .05 \\
$\begin{array}{lccc}\text { Uncertainty Concerning } \\
\text { Treatment }\end{array}$ & $5.77 \pm 20.17$ & $6.08 \pm 20.48$ & .22 \\
$\begin{array}{l}\text { Patients and their Families } \\
\text { Discrimination }\end{array}$ & $5.42 \pm 16.72$ & $5.49 \pm 16.31$ & .19 \\
$\begin{array}{l}\text { Total Occupational Stress } \\
\text { Score }\end{array}$ & $2.91 \pm 2.96$ & $2.91 \pm 2.96^{\mathrm{a}}$ & \\
\hline
\end{tabular}

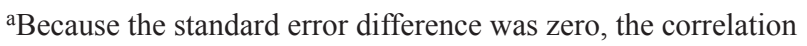
was not done.

Using paired $t$ test; $p<.05$ 
Comparing the total occupational stress score between the study groups in pre-test and post-test, no significant difference was observed (Table 4).

In the pre-test subscale comparison between groups, the scores of conflict with physicians, problems relating to supervisors, work load, and uncertainty concerning the treatment in the intervention group were significantly higher than the control group in the pre-test $(p<.05)$.

In the post-test subscale comparison, the results show no significant difference between the study groups.

A one-way ANCOVA was conducted to determine a statistically significant difference between massage and EMS staff's occupational stress level controlled for pre-test score, after examining the assumptions of this test, including normality, homogeneity of variance, linear correlation between pre-test and post-test, and regression slope equality in two groups. Results showed that there is a significant effect of massage on EMS staff's occupational stress level after controlling for pre-test score $(p=.001)$ (Table 5).

Table 3. Comparing Pre-Test and Post-Test Score of the Total Occupational Stress and all Subscales Scores in Massage Group

\begin{tabular}{lccc}
\hline & Pre-Test & Post-Test & $\begin{array}{c}p \\
\text { value }\end{array}$ \\
\cline { 2 - 3 } & Mean \pm SD & Mean $\pm S D$ & \\
\hline $\begin{array}{l}\text { Death and Dying } \\
\text { Conflict with Physicians }\end{array}$ & $3.63 \pm 16.86$ & $13.75 \pm 2.87$ & .001 \\
$\begin{array}{l}\text { Inadequate Emotional } \\
\text { Preparation }\end{array}$ & $2.20 \pm 6.17$ & $7.06 \pm 2.38$ & .015 \\
$\begin{array}{l}\text { Problems Relating to Peers } \\
\text { Problems Relating to }\end{array}$ & $3.98 \pm 10.79$ & $9.55 \pm 3.52$ & .006 \\
$\begin{array}{l}\text { Supervisors } \\
\text { Work Load }\end{array}$ & $3.95 \pm 13.86$ & $17.24 \pm 4.94$ & .001 \\
$\begin{array}{l}\text { Uncertainty Concerning } \\
\text { Treatment }\end{array}$ & $5.22 \pm 21.86$ & $4.58 \pm 18.86$ & .001 \\
$\begin{array}{l}\text { Patients and their Families } \\
\text { Discrimination }\end{array}$ & $5.51 \pm 21.31$ & $5.53 \pm 25.06$ & .001 \\
$\begin{array}{l}\text { Total Occupational Stress } \\
\text { Score }\end{array}$ & $2.19 \pm 2.96^{\mathrm{a}}$ & $2.19 \pm 2.24$ & .001 \\
\hline
\end{tabular}

aBecause the standard error difference was zero, the correlation was not done.

Using paired $t$ test; $p<.05$

TABle 4. Comparing Mean Score of the Total Occupational Stress Between the Two Groups

\begin{tabular}{|c|c|c|c|}
\hline & \multicolumn{2}{|c|}{ Massage Group Control Group } & \multirow{2}{*}{$\underset{\text { value }}{p}$} \\
\hline & Mean $\pm S D$ & Mean $\pm S D$ & \\
\hline Total Occupational Post-test & $110.41 \pm 21.75$ & $112.58 \pm 30.62$ & .56 \\
\hline Stress Score $\quad$ Pre-test & $130.20 \pm 26.45$ & $114.41 \pm 30.11$ & .023 \\
\hline
\end{tabular}

Using independent $t$ test; $p<.05$

\section{DISCUSSION}

The findings of the present study indicated that receiving Swedish massage as a complementary medical procedure can significantly reduce occupational stress in the operational staff of EMS centres.

In a review of the literature, various studies using different methodologies and designs have worked on the short-term and long-term effects of massage therapy (used as a standalone measure or in combination with other complementary medical interventions) by the Chair or the therapist on the level of occupational stress among the personnel of the health-care system. Certain contradictory reports have been documented on this topic. Some researchers have introduced massage therapy as a standalone measure, or in combination with other complementary medical interventions, as an effective intervention in decreasing occupational stress, ${ }^{(3,26,28)}$ while the results of some other studies suggest the inefficiency of massage on occupational stress. ${ }^{(8,17)}$ Although different rates of efficacy of this intervention exist in various individuals, occupations, and organizational situations, and the manual or electronic performance of the massage seems logical in the long-run and the short-run, there are limited scientific reports on the efficacy of this intervention in diminishing occupational stress among EMS staff.

On the other hand, what the scholars have found about the results of numerous review studies on the effects of massage therapy indicates that this therapeutic modality promotes relaxation responses, playing a significant role in controlling occupational stress. In this regard, researchers have found that massage therapy, especially with moderate pressure, can attenuate depression, anxiety, and heart rate, thereby correcting patterns of electric activity in the brain such that the effect of a moderate massage at different zones of the brain, which play a role in regulating stress and emotions (including the anterior cingulated cortex, the amygdala, and the hypothalamus), are visible in functional magnetic resonance imaging (MRI) data. ${ }^{(25,27)}$

A review of related literature revealed the nurses' inclinations for the use of complementary methods for reducing occupational stress such that most nurses

TABLE 5. Summary of Results of Covariance (ANCOVA) for Effectiveness of Massage on EMS Staff's Occupational Stress of Experimental Group with Covariance of Pre-Test

\begin{tabular}{|c|c|c|c|c|c|c|}
\hline Variable & $\begin{array}{c}\text { Source } \\
\text { of } \\
\text { Changes }\end{array}$ & $\begin{array}{c}\text { Sum } \\
\text { of } \\
\text { Squares }\end{array}$ & df $\begin{array}{c}\text { Mean } \\
\text { Square }\end{array}$ & $F$ & $\begin{array}{c}p \\
\text { value }\end{array}$ & $\begin{array}{c}\text { Partial } \\
\text { Eta } \\
\text { Squared }\end{array}$ \\
\hline \multirow{2}{*}{ ENSS } & Pre-test & 32763.560 & 132763.560 & 306.019 & 9.000 & .848 \\
\hline & Group & 4713.374 & 14713.374 & 44.024 & .000 & .445 \\
\hline
\end{tabular}


reported the use of one or more of body-mind exercises to decrease occupational stress. ${ }^{(12)}$ In another study, most nurses have preferred and suggested the use of various methods of complementary medicine, such as music therapy and massage therapy, to decrease the adverse mental effects of the work environment. ${ }^{(7)}$ Hence, it may be concluded that the required background is ready for the implementation of this therapeutic method. Considering the different natures of work environments, social interactions, and the patients with whom the EMS personnel work, and also given that these individuals have enough free time for performing complementary medical interventions on their colleagues, it appears that the teaching of these methods and their implementation by peer groups is an easy, cost-effective, and useful method for promoting the physical, mental, and social health of these professionals.

\section{CONCLUSION}

This study showed that massage therapy is an effective way to reduce occupational stress in EMS staff. Therefore, EMS managers can promote the application of massage therapy as an effective, simple, uncomplicated method in emergency medical centres to reduce occupational stress.

\section{ACKNOWLEDGMENTS}

The manuscript is derived from a master degree thesis. The authors acknowledge their gratitude to the Research and Technology Deputy of Rafsanjan University of Medical Sciences, Rafsanjan, Iran, for the financial support to the project, and also to the emergency medical service staff who cooperated with the study.

\section{CONFLICT OF INTEREST NOTIFICATION}

The authors declare there are no conflicts of interest.

\section{COPYRIGHT}

Published under the CreativeCommons AttributionNonCommercial-NoDerivs 3.0 License.

\section{REFERENCES}

1. Gholamzadeh S, Sharif F, Rad FD. Sources of occupational stress and coping strategies among nurses who work in Admission and Emergency Departments of Hospitals related to Shiraz University of Medical Sciences. Iranian J Nursing Midwifery Res. 2011;16(1):41-46.
2. Guise J-M, Hansen M, O'Brien K, Dickinson C, Meckler G, Engle P, et al. Emergency medical services responders' perceptions of the effect of stress and anxiety on patient safety in the out-of-hospital emergency care of children: a qualitative study. BMJ Open. 2017;7(2).

3. Ruotsalainen J, Serra C, Marine A, Verbeek J. Systematic review of interventions for reducing occupational stress in health care workers. Scandinavian J Work, Environ Health. 2008;34(3):169-178.

4. Mishra S, Goebert D, Char E, Dukes P, Ahmed I. Trauma exposure and symptoms of post-traumatic stress disorder in emergency medical services personnel in Hawaii. Emergency Med J. 2010;27(9):708-711.

5. Froutan R, Khankeh HR, Fallahi M, Ahmadi F, Norouzi K. Resiliency improvements in medical emergency staff in burn missions: a qualitative Study in an Iranian context. Iranian Red Crescent Med J. 2015;17(7):e22495.

6. Bernaldo-De-Quiros M, Piccini AT, Gomez MM, Cerdeira JC. Psychological consequences of aggression in pre-hospital emergency care: cross sectional survey. International J Nurs Studies. 2015;52(1):260-270.

7. Happell B, Dwyer T, Reid-Searl K, Burke KJ, Caperchione CM, Gaskin CJ. Nurses and stress: recognizing causes and seeking solutions. J Nurs Management. 2013;21(4):638-647.

8. Cooke M, Holzhauser K, Jones M, Davis C, Finucane J. The effect of aromatherapy massage with music on the stress and anxiety levels of emergency nurses: comparison between summer and winter. J Clin Nurs. 2007;16(9):1695-1703.

9. Sterud T, Hem E, Ekeberg Ø, Lau B. Occupational stressors and its organizational and individual correlates: A nationwide study of Norwegian ambulance personnel. BMC Emergency Med. 2008;8:16.

10. Sung M-H, Oh M-O. The relationships of professional self-concept, role conflict and job satisfaction on emergency department nurses. J Korean Acad Fundamentals Nurs. 2011;18(1):107-115.

11. Ghaniyoun A, Shakeri K, Heidari M. The association of psychological empowerment and job burnout in operational staff of Tehran emergency center. Indian J Crit Care Med. 2017;21(9):563-567.

12. Kemper K, Bulla S, Krueger D, Ott MJ, McCool JA, Gardiner P. Nurses' experiences, expectations, and preferences for mindbody practices to reduce stress. BMC Complement Altern Med. 2011;11(1):26.

13. Skogstad M, Skorstad M, Lie A, Conradi H, Heir T, Weisæth L. Work-related post-traumatic stress disorder. Occupational Med (Oxford, England). 2013;63(3):175-182.

14. Marzec ML, Scibelli A, Edington D. Impact of changes in medical condition burden index and stress on absenteeism among employees of a US utility company. Int $J$ Workplace Health Management. 2015;8(1):15-33.

15. Khamisa N, Oldenburg B, Peltzer K, Ilic D. Work related stress, burnout, job satisfaction and general health of nurses. Int $J$ Environment Res Public Health. 2015;12(1):652-666.

16. Guthrie R, Ciccarelli M, Babic A. Work-related stress in Australia: The effects of legislative interventions and the cost of treatment. Int J Law Psychiatry. 2010;33(2):101-115.

17. Back C, Tam H, Lee E, Haraldsson B. The effects of employerprovided massage therapy on job satisfaction, workplace stress, and pain and discomfort. Holistic Nurs Pract. 2009;23(1):19-31. 
18. Huerta-Franco M-R, Vargas-Luna M, Tienda P, DelgadilloHoltfort I, Balleza-Ordaz M, Flores-Hernandez C. Effects of occupational stress on the gastrointestinal tract. World $J$ Gastrointest Pathophysiol. 2013;4(4):108-118.

19. Pirrallo RG, Loomis CC, Levine R, Woodson BT. The prevalence of sleep problems in emergency medical technicians. Sleep Breathing. 2012;16(1):149-162.

20. Rahimi A, Vazini H, Alhani F, Anoosheh M. Relationship between low back pain with quality of life, depression, anxiety and stress among emergency medical technicians. Trauma Monthly. 2015;20(2):e18686.

21. Tamers SL, Okechukwu C, Bohl AA, Guéguen A, Goldberg M, Zins M. The impact of stressful life events on excessive alcohol consumption in the French population: findings from the GAZEL cohort study. PloS One. 2014;9(1):e87653.

22. Essex B, Scott LB. Chronic stress andassociated coping strategies among volunteer EMS personnel. Prehospital Emergency Care. 2008;12(1):69-75.

23. Gallagher S, McGilloway S. Experience of critical incident stress among ambulance service staff and relationship to psychological symptoms. Int J Emerg Mental Health. 2009;11(4):235-248.

24. Chopko BA, Palmieri PA, Adams RE. Associations between police stress and alcohol use: Implications for practice. $J$ Loss Trauma. 2013;18(5):482-497.

25. Field T. Massage therapy research review. Complement Therap Clin Pract. 2016;24:19-31.
26. Engen DJ, Wahner-Roedler DL, Vincent A, Chon TY, Cha SS, Luedtke CA, et al. Feasibility and effect of chair massage offered to nurses during work hours on stress-related symptoms: a pilot study. Complement Therap Clin Pract. 2012;18(4):212-215.

27. Field T. Massage therapy research review. Complement Therap Clin Pract. 2014;20(4):224-229.

28. Nazari F, Mirzamohamadi M, Yousefi H. The effect of massage therapy on occupational stress of Intensive Care Unit nurses. Iranian J Nurs Midwifery Res. 2015;20(4):508-515.

29. Pandis N. Randomization. Part 2: minimization. Am J Orthodont Dentofac Orthoped. 2011;140(6):902-904.

30. Field T, Diego M, Hernandez-Reif M. Moderate pressure is essential for massage therapy effects. Int $J$ Neurosci. 2010;120(5):381-385.

31. Day A, Gillan L, Francis L, Kelloway E, Natarajan M. Massage therapy in the workplace: Reducing employee strain and blood pressure. G Ital Med Lav Ergon. 2009;31(3 Suppl B):B25-B30.

32. French SE, Lenton R, Walters V, Eyles J. An empirical evaluation of an expanded nursing stress scale. J Nurs Measurement. 2000;8(2):161-178.

Corresponding author: Tayebeh Negahban Bonabi, Department of Community Health Nursing, Community Health Nursing Department, School of Nursing and Midwifery, Parastar Street, Rafsanjan, Kerman Province, Iran

E-mail: negahbant@yahoo.com 